\title{
Dynamics of Communication Barriers on Public Institutions; The Case of NDU Council, North West Region Cameroon
}

\author{
Massa Ernest Massa \\ Lecturer at Higher Technical Teachers Training College (H.T.T.T.C) Kumba, University of Buea, \\ Researcher at "Foundation of Scientific Research, Community Based Rehabilitation and Advocacy on \\ Inclusive Education" (FORCAIE-CAMEROON)

\section{Dr. Lukong Kenneth Mengjo} \\ Lecturer / Dean of Studies, at Higher Technical Teachers, Training College (H.T.T.T.C) Kumba, \\ University of Buea
}

\begin{abstract}
This paper presents a study of the effects of communication barriers within the institutional management. Practice has shown that the lack of communication or of understanding makes the various segments of the same social body live on different coordinates. The modern world, the knowledge society is based on the principles of communication. No organization would admit its internal or external lack of communication, now, when the era of computers and high technology is growing fast. No corporation would admit that communication is in fact such a personal element and it is an attribute of each member placed in the hierarchy of the organization. Even when noticing the lack of communication, the problems which it causes the organization, limited managers, managers who only seek to perform daily activities with no perspectives, will not take the measures which are imposed in these situations. The lack of communication entails dissatisfaction, conflicts, it impedes development and it leads to the decline of the company which lacks communication. In this study we will refer to the main barriers of communication we have identified in the academic organizational environment, barriers of communication which co-exist in the internal environment, in the communication with the external one, with the target public of the academic organization, elements of the relation which in most cases prevents the public institution from accomplishing its mission or to reach its objectives. Public institutions are rigid organizations, characterized by a hierarchical structure, often slow in reacting. Changes are mostly induced by outside forces, either political opinions or international organizations that set structural standards that the institutions must comply with. But when it comes to changing people - their mentality, the way they act/react all bets are off, as there are social and psychological factors that enter the equation. This study investigates the effects of communication barriers on public institutions, how communication could be use to create adaptive mechanisms in their institutions. Whenever change is being implemented, the fear factor can set in. This can be the fear of change itself and its consequences such as the possible loss of job security or loss of responsibility or control. Continuous, honest and open communication is essential in such cases, because change can take people out of their "comfort zone" and raise their stress levels. The challenge is to communicate the right message that the "new zone" is even more comfortable and secure, or at least it will be once the initial short-term discomfort of implementing change has been overcome. The study concludes that knowing how, what, when, to whom and how much to communicate is essential for institutions going through communication barriers and it can help motivate the employees and gain understanding and support from the community.
\end{abstract}

Keywords: Dynamics of Communication Barriers and Public Institutions

\section{INTRODUCTION}

Due to political and societal demands public sector organizations or institutions are in a constant process of adapt to changing circumstances in order to remain effective, efficient and legitimate in dealing with societal problems and delivering public services. Accompanying changes may be incremental, when improvements can be achieved by relatively small adjustments within a dominant policy paradigm, or new technologies fit with existing regulations, but may also be larger, when fundamental change is needed to maintain, improve or alter the service level of the public sector organization. The call to foster and fasten innovations in the public domain is expressed by many think tanks and governmental organizations like the World Bank and the OECD. This raises the question what capacities public sector organizations need to be able to deal with the different 
challenges of realizing incremental change as well as radical innovation. The modern world, the knowledge society is based on the principles of communication. No organization would admit its internal or external lack of communication, now, when the era of computers and high technology is growing fast. No corporation would admit that communication is in fact such a personal element and it is an attribute of each member placed in the hierarchy of the organization. All we do is communicate. But either because of the fear to discover unpleasant aspects or because we are in a hurry, we avoid to analyze the way in which we do it, the way in which we measure the quality of communication, how much the managerial communication matters in an organization and how dominant informal communication is. [1] Even when noticing the lack of communication, the problems which it causes the organization, limited managers, managers who only seek to perform daily activities with no perspectives, will not take the measures which are imposed in these situations.

The lack of communication entails dissatisfaction, conflicts, it impedes development and it leads to the decline of the company which lacks communication. Communication doesn't only define the transmission of a piece of information. To communicate means to be open to change and it reflects the attitude of giving sense to a certain reality. At the same time, communication is a mechanism, an aid. Just as the word represents an instrument for thought, communication is a practical mechanism which serves organizations. [2] Above the transmission of information inside and outside the organization, it needs to prepare the environment in which it will be transmitted. The organization needs to prepare a strategy of „occupation” of the public space, taking into consideration the environment, the social reality and the expectations of the community it belongs to. In a simplified version, institutional communication represents the speech of institutions (public, private, associative) about themselves. Therefore, it doesn't represent the speech about the products or the services offered by the organization. By looking from a complementary point of view, institutional communication refers to the nature of the institution, to its legitimacy, principles, mission, personality, objectives, actions or performance. The field of institutional communication lies from the internal communication to the high level one, from the financial communication to the one about the image of the institution, of its managerial team or of its performance. Institutional communication aims to present the set of activities of the organization and the way in which its identity and image are presented. Institutional communication is part of the development policy of the institution. We are refering to a global communication which can be complex and held under control if it rightly assumes the preoccupations of communicating with the exterior and the interior at the same time. The diversity of public institutions and of the relationships with the citizens calls for the need of necessity. To communicate well means, above all, that the sender should know his role and he should communicate it to the public. The importance of institutional communication resides in the fact that it bears the mission to emphasize the policy of the institution, which implies the permanent presentation of the strategy, structures and identity.

The study of communication is important, because every administrative function and activity involves some form of direct or indirect communication. Whether planning and organizing or leading and monitoring, school administrators communicate with and through other people. This implies that every person's communication skills affect both personal and organizational effectiveness (Brun, 2010; Summers, 2010). It seems reasonable to conclude that one of the most inhibiting forces to organizational effectiveness is a lack of effective communication (Lutgen-Sandvik, 2010). Moreover, good communication skills are very important to ones success as a school administrator. A recent study indicated that recruiters rated communication skills as the most important characteristic of an ideal job candidate (Yate, 2009). This article helps to better understand how institutional administrators can improve their communication skills.

\section{BACKGROUND OF THE STUDY}

Competence in oral communication - in speaking and listening - is prerequisite to students' academic, personal, and professional success in life. Indeed, teachers deliver most instruction for classroom procedures orally to students. Students with ineffective listening skills fail to absorb much of the material to which they are exposed. Their problems are intensified when they respond incorrectly or inappropriately because of poor speaking skills. Students who cannot clearly articulate what they know may be wrongly udged as uneducated or poorly informed. Additionally, some speech styles of students can trigger stereotyped expectations of poor ability: expectations that may become selffulfilling. Of equal concern, students who are unable to effectively ask for help from a teacher will not 
receive it, and typically reticent students progress more slowly despite what may be a normal level of aptitude. Beyond the confirms of school, oral communication competence can contribute to individuals' social adjustment and participation in satisfying interpersonal relationships.

Communication is not a new term but has only recently achieved some degree of recognition as a field of academic study especially in relation to Public Institutions. It requires active involvement of those to whom the messages are directed as well as of those who originate them. It cannot be handled or talk of independently or single handedly without information. This is because Communication itself is not of any importance without information. It is information that is being communicated. It is a process beginning with a sender who encodes the message and passes it through some channel to the receiver who decodes the message. It is fruitful if and only if the message sent by the sender is interpreted with the same meaning by the receiver. It is generally thought of as the exchange of information between two or more people using the means of shared symbols or signs. According to Kathryn A. Baker managers have traditionally spent the majority of their time communicating in one form or another (meetings, face to face discussions, memos, letters, e- mails, reports, etc). Today, however, more employees find that an important part of their work is communication especially now that service workers outnumber production workers and research as well as production processes emphasize greater collaboration and teamwork among workers in different functional groups.

From the earliest times, people needed to communicate across distance or over time. Since the beginnings of writing, communication media have allowed messages to travel over distance and time. A communication medium is a means for recording and transporting a message or information. The word medium comes from the Latin word medius, meaning middle or between. It is a channel or path for sending a message between communicators. A single channel such as radio, or a book, or the telephone is called a medium; media is plural, meaning more than one medium. Public institutions are concerned with communication in several ways. Some institutions build and install communication equipment, such as fax (facsimile) machines, video cameras, CD players, printing presses, personal computers, and telephones. Other companies create some of the messages or content that those technologies carry, such as movies, books, and software. These institutions are part of the media or telecommunications industries. Institutional communication is important in every business. People in institutions need to communicate to coordinate their work and to inform others outside the institution about their activities and services (these kinds of communication are called public relations).

The most basic form of interpersonal communication is a dyad (an encounter or conversation between two people). Some dyads exist over a long period of time, as in a marriage or partnership. Communicating well in institutions requires good conversational skills. Communicators must know how to start and end the conversation, how to make themselves understood, how to respond to fellow workers, how to be sensitive to their concerns, how to take turns, and how to listen. Together, these abilities are called communication competence. Shyness or reluctance to interact is called communication apprehension. Persuasion is the process of convincing others that one's ideas or views are valuable or important. The role of Communication in Public Institutions cannot be over emphasized. Communication has largely grown in response to the needs and concerns of the Public Institutional success or goals. Moreover, a sea- change in Communication technologies has contributed to the transformation of modern Communication, although it depends the way they are used. The $19^{\text {th }}$ century experienced an unexpected change in Communication technology with some scientific discoveries (electronic age) that enhanced Communication. Communicating information over long distances is no longer the works of letters alone as seen in the past, but telephones, internet and others. All these discoveries were steps towards better communication which constitute verbal and non-verbal Communication. Photography was an example of a non- verbal means of modern communication. At first, pictures were done by hand (drawing, painting) and best communicated certain ideas, but the discovery of cameras was great advancement in the production of pictures and more interestingly offered better images than the act of drawing could. Cameras made picture production easier and strengthened mass communication. Alfred Stieglitz had through a process of photochemistry discovered photography in 1833, while Nicephore Niepce took the first permanent photograph in 1825. Telegraphs came into existence and a telephone which is a verbal means of communication was first used by Alexander Graham Bell in 1876.

The first Communication programs where typically located in speech departments, but most business schools now include Public Institutional Communication as a key element of study. The twentieth and the twenty first century Communication gave birth to the invention of radio and Television. 
According to McGaughey, this period falls under the fourth and fifth epoch of civilization that is electronic recording and broadcasting and computer communication. The study of Public Institutional Communication recognizes that Communication in institutions goes as far beyond training administrators to be effective speakers and to have good interpersonal Communication skills. Moreover, it recognizes that all institutions, not just business Institutions, have Communication needs and challenges. Information is the life blood of any Public Institution and needs to flow freely to be effective. For any public institution to be successful, it requires downward Communication to subordinates, upward Communication to superiors, and horizontal Communication to peers in other divisions. Downward Communication is more than passing on information to subordinates. It may involve effectively managing the tone of the message, as well as showing skill in delegation to ensure the job is done effectively by the right person. In upward Communication, tone is even more crucial as are timing, strategy, and audience adaptation. In neither case can the manager operate on automatic as the messages are sent out.

Communication process, or the steps taken to get message from one mind to another, seems simple enough. As the definition at the opening suggested, the sender has an idea, which he transmits to the receiver through signs - physical sensations capable of being perceived by another. These signs might be a printed or spoken word, a gesture, a hand- shake, or a stern look, to name just a few. The receiver takes those signs, interprets them and reacts with feedback. Communication barriers (often also called noise or static) complicate the communication process. Communication barrier is anything that impedes the communication process. These barriers are inevitable, while they cannot be avoided, both the sender and receiver can work to maximized them.

Employees with poor communication skills are sometimes viewed as less attractive by their peers and enjoy fewer friendships. Antisocial and violent behaviors often accompany or occur with underdeveloped social and conflict management skills. On the positive side, the ability to communicate orally supports sound psychological development. One's self concept is acquired through interaction with others. In psychological terms, achieving self-actualization involves communication activities such as making contributions in groups, exerting influence over others, and using socially acceptable behavior. As individuals mature and become working adults, communication competence continues to be essential. Communication skills are required in most occupations. Employers identify communication as one of the basic competencies every graduate should have, asserting that the ability to communicate is valuable for obtaining employment and maintaining successful job performance. The communication skills essential in the workplace include basic oral and writing skills, and the ability to communicate in work groups and teams with persons of diverse background, and when engaged in problem solving and conflict management. Given the importance of the ability to communicate competently, the communication discipline should be viewed as central on college campuses. Humans are born with the ability to vocalize; but not with the knowledge, attitudes, and skills that define communication competence. The ability to communicate effectively and appropriately is learned and, therefore, must be taught. To provide credence for this argument, this article provides a description of nearly one hundred articles, commentaries, and publications, which emphasize the importance of communication and the role of the study of communication in contemporary life. These publications include books, journals, newspaper articles, and conference papers, which have utilized both qualitative and quantitative methods. From these materials, five major themes, developed and supported by sub-themes, emerge. These include the role of communication education in developing the whole person, in improving the work of education, in advancing the interests of society and in bridging cultural differences, and in advancing careers and the business enterprise. A final theme is that these contributions can best be realized when communication is taught by specialists in departments that are devoted to the study of communication.

\section{Statement of the Problem}

Communication is the life blood of any Public Institution. Many Institutions have collapsed due to poor Communication or ineffectiveness in Communication. Communication is the key factor in the success of any Public Institution. When it comes to effective Communication, there are certain barriers that every Public institution faces. What makes Communication complex, difficult and frustrating are the barriers that come in its way. Many institutions do not even try to identify some of these communication barriers. Institutions turn to achieve little of their stated goals due to barriers in Communication. The problem statement of this research is based on the effects posed by Communication barriers on the efficiency of Public institutions. 


\section{Objectives of the Study}

The objectives of this research study were,

1) To investigate into the barriers of Communication and its consequences on Public institutions.

2) To identify the types of Communication barriers and how those barriers prevent the success of institutions.

3) To let the Administrators of institutions in general and the Ndu Council Administrators in particular to know that there exist barriers in Communication which at times hinders the achievement of goals but mostly are unnoticed?

4) To identify those administrative misunderstanding and disfunctioning of the enterprise or Public Institution is resulting from Communication barriers.

\section{DEFINITION OF CONCEPTS}

\section{Defining Communication and Describing the Process}

Communication can be defined as the process of transmitting information and common understanding from one person to another (Keyton, 2011). The word communication is derived from the Latin word, communis, which means common. The definition underscores the fact that unless a common understanding results from the exchange of information, there is no communication. (Cheney, 2011)

Two common elements in every communication exchange are the sender and the receiver. The sender initiates the communication. In a school, the sender is a person who has a need or desire to convey an idea or concept to others. The receiver is the individual to whom the message is sent. The sender encodes the idea by selecting words, symbols, or gestures with which to compose a message. The message is the outcome of the encoding, which takes the form of verbal, nonverbal, or written language. The message is sent through a medium or channel, which is the carrier of the communication. The medium can be a face-to-face conversation, telephone call, e-mail, or written report. The receiver decodes the received message into meaningful information. Noise is anything that distorts the message. Different perceptions of the message, language barriers, interruptions, emotions, and attitudes are examples of noise. Finally, feedback occurs when the receiver responds to the sender's message and returns the message to the sender. Feedback allows the sender to determine whether the message has been received and understood. The elements in the communication process determine the quality of communication. A problem in any one of these elements can reduce communication effectiveness (Keyton, 2011). For example, information must be encoded into a message that can be understood as the sender intended. Selection of the particular medium for transmitting the message can be critical, because there are many choices. For written media, a school administrator or other organization member may choose from memos, letters, reports, bulletin boards, handbooks, newsletters, and the like. For verbal media, choices include face-to-face conversations, telephone, computer, public address systems, closed-circuit television, tape-recorded messages, sound/slide shows, e-mail, and so on. Nonverbal gestures, facial expressions, body position, and even clothing can transmit messages. People decode information selectively. Individuals are more likely to perceive information favorably when it conforms to their own beliefs, values, and needs (Keyton, 2010). When feedback does not occur, the communication process is referred to as one-way communication. Two-way communication occurs with feedback and is more desirable.

The key for being successful in the contemporary school is the ability of the school administrator to work with other school stakeholders (faculty, support staff, community members, parents, central office); and develop a shared sense of what the school/school district is attempting to accomplish where it wants to go, a shared sense of commitments that people have to make in order to advance the school/school district toward a shared vision and clarity of goals. As school administrators are able to build a shared mission, vision, values, and goals, the school/school district will become more effective. Building a relationship between school administrators and other school stakeholders requires effective communication. For example, research indicates that principals spend 70 to $80 \%$ of their time in interpersonal communication with various stakeholders (Green, 2010; Lunenburg \& Irby, 2006; Matthews \& Crow, 2010; Sergiovanni, 2009; Tareilo, 2011; Ubben, Hughes, \& Norris, 2011). Effective principals know how to communicate, and they understand the importance of ongoing communication, both formal and informal: faculty and department meetings; individual conversations with parents, teachers, and students; and telephone calls and e-mail messages with various stakeholder 
groups. The one constant in the life of a principal is a lot of interruptions they happen daily, with a number of one- and three-minute conversations in the course of the day. This type of communication in the work of the principal has to be done one on one - one phone call to one person at a time, one parent at a time, one teacher at a time, one student at a time; and a principal needs to make time for these conversations. For example, a principal may be talking with a parent with a very serious problem. She may be talking with a community member. She may be talking with the police about something that went on during the school day. The administrator must be able to turn herself on and off in many different roles in any given day.

\section{BARRIERS TO EFFECTIVE COMMUNICATION}

A school administrator has no greater responsibility than to develop effective communication (Pauley, 2010). Why then does communication break down? On the surface, the answer is relatively simple. I have identified the elements of communication as the sender, the encoding, the message, the medium, the decoding, the receiver, and the feedback. If noise exists in these elements in any way, complete clarity of meaning and understanding does not occur. The author, George Bernard Shaw wrote, IThe greatest problem with communication is the illusion that it has been accomplishedll (Shaw, 2011). Four types of barriers (called noise, process barriers, physical barriers, semantic barriers, and psychosocial barriers (Eisenberg, 2010).

\subsection{Process Barriers}

Every step in the communication process is necessary for effective and good communication.. Blocked steps become barriers. Consider the following situations:

1) Sender barrier. A new administrator with an innovative idea fails to speak up at a meeting, chaired by the superintendent, for fear of criticism.

2) Encoding barrier. A Spanish-speaking staff member cannot get an English-speaking administrator to understand a grievance about working conditions.

3) Medium barrier. A very upset staff member sends an emotionally charged letter to the leader instead of transmitting her feelings face-to-face.

4) Decoding barrier. An older principal is not sure what a young department head means when he refers to a teacher as "spaced out."

5) Receiver barrier. A school administrator who is preoccupied with the preparation of the annual budget asks a staff member to repeat a statement, because she was not listening attentively to the conversation.

6) Feedback barrier. During a meeting, the failure of school administrators to ask any questions causes the superintendent to wonder if any real understanding has taken place. Because communication is a complex, give-and-take process, breakdowns anywhere in the cycle can block the transfer of understanding.

\subsection{Physical Barriers}

Any number of physical distractions can interfere with the effectiveness of communication, including a telephone call, drop-in visitors, and distances between people, walls, and static on the radio. People often take physical barriers for granted, but sometimes they can be removed. For example, an inconveniently positioned wall can be removed. Interruptions such as telephone calls and drop-in visitors can be removed by issuing instructions to a secretary. An appropriate choice of media can overcome distance barriers between people.

\subsection{Semantic Barriers}

The words we choose, how we use them, and the meaning we attach to them cause many communication barriers. The problem is semantic, or the meaning of the words we use. The same word may mean different things to different people. Words and phrases such as efficiency, increased productivity, management prerogatives, and just cause may mean one thing to a school administrator, and something entirely different to a staff member. Technology also plays a part in semantic barriers to communication. Today's complex school systems are highly specialized. Schools have staff and technical experts developing and using specialized terminology jargon that only other similar staff and technical experts can understand. And if people don't understand the words, they cannot understand the message. 


\subsection{Psychosocial Barriers}

Three important concepts are associated with psychological and social barriers: fields of experience, filtering, and psychological distance (Antos, 2011)). Fields of experience include people's backgrounds, perceptions, values, biases, needs, and expectations. Senders can encode and receivers decode messages only in the context of their fields of experience. When the sender's field of experience overlaps very little with the receiver's, communication becomes difficult. Filtering means that more often than not we see and hear what we are emotionally tuned in to see and hear. Filtering is caused by our own needs and interests, which guide our listening. Psychosocial barriers often involve a psychological distance between people that is similar to actual physical distance. For example, an institutional administrator talks down to a staff member, who resents this attitude, and this resentment separates them, thereby blocking opportunity for effective communication. Successful communication by administrators is the essence of a productive institutional organization. However, as discussed previously, communications do break down. Several communication theorists (Abrell, 2004; Auer, 2011; Larson, 2011; Shettleworth, 2010; Weiss, 2011) have focused on the major areas where failures in communication most frequently occur. The following are the major areas where communication breakdowns most frequently occur in schools: - Sincerity. Nearly all communication theorists assert that sincerity is the foundation on which all true communication rests. Without sincerity-honesty, straightforwardness, and authenticity all attempts at communication are destined to fail.

1) Empathy. Research shows that lack of empathy is one of the major obstacles to effective communication. Empathy is the ability to put one's self into another's shoes. The empathetic person is able to see the world through the eyes of the other person.

2) Self-perception. How we see ourselves affects our ability to communicate effectively. A healthy but realistic self-perception is a necessary ingredient in communicating with others.

3) Role perception. Unless people know what their role is, the importance of their role, and what is expected of them, they will not know what to communicate, when to communicate, or to whom to communicate.

4) Efforts to distort the message. Pitfalls in communication often occur in our efforts-both consciously and unconsciously to distort messages.

5) Images. Another obstacle to successful communication is the sender's image of the receiver and vice versa. For example, on the one hand, school administrators are sometimes viewed as not too well informed about teaching, seen as out of touch with the classroom, and looked on as paper shufflers. On the other hand, some institutional administrators view colleagues as lazy, inconsiderate of administrative problems, and unrealistic about the strengths and weaknesses of their students. Such views lead to a "we-they" attitude.

6) Vehicle for message. The vehicle by which we choose to send messages is important in successful communication. In most cases, the vehicle to be used is defined by the situation.

7) Ability to communicate. Some of the ways we communicate raise barriers by inhibiting discussion or causing others to feel inferior, angry, hostile, dependent, compliant, or subservient.

8) Listening ability. Frequently, people fail to appreciate the importance of listening, do not care enough to become actively involved with what others are saying, and are not sufficiently motivated to develop the skills necessary to acquire the art of listening.

9) Culture. Our cultural heritage, biases, and prejudices often serve as barriers to communication. The fact that we are African-American or white, young or old, male or female have all proved to be obstacles in communicating effectively.

10) Tradition. Past practice in a school helps determine how, when, and what we send and receive. For example, a school administrator who has an authoritative style may find that his staff will not share information readily. If a new administrator with a collaborative style replaces the authoritarian one, the new administrator may find that it takes a while for his colleagues to speak out on important issues.

11) Conditioning. The manner in which communication is conditioned by the environment influences the accuracy of messages sent and received. If we work for administrators who set a climate in 
which we are encouraged to share information, we soon become conditioned to communicate accordingly.

12) Noise. A major barrier to communication is what communication experts call noise. Noise consists of the external factors in the channels and the internal perceptions and experiences within the source and the receiver that affect communication.

13) Feedback. Faculty and staff tell their leaders that they want feedback. However, feedback improperly given can impede communication rather than improve it. Administrators and followers both need more training in how to use feedback more productively.

\section{IMPROVING COMMUNICATION EFFECTIVENESS WITHIN INSTITUTIONS}

Effective communication is a two-way process that requires effort and skill by both sender and receiver. Administrators will at times assume each of these roles in the communication process. In this section, I discuss guidelines for improving communication effectiveness, including senders' and receivers' responsibilities, and listening.

\section{SENDER'S RESPONSIBILITIES}

Several communication theorists (Cheney, 2011; Keyton, 2011; Tourish, 2010) have gleaned Ten Commandments of good communication, which are particularly applicable to the sender. These commandments, together with a basic understanding of the communication process itself, should provide a good foundation for developing and maintaining an effective set of interpersonal communication skills, which school administrators can use when communicating with various school stakeholders.

1) Institutional administrators need to clarify their ideas before communicating. The more systematically administrators analyze the problem or idea to be communicated, the clearer it becomes. This is the first step toward effective communication. Many communications fail because of inadequate planning. Good planning must consider the goals, attitudes, and needs of those who will receive the communication and those who will be affected by it.

2) Administrators need to examine the true purpose of each communication. Before administrators communicate, they must ask themselves what they really want to accomplish with their message - obtain information, initiate action, or change another person's attitude? Administrators need to identify their most important goal and then adapt their language, tone, and total approach to serve that specific objective. Administrators should not try to accomplish too much with each communication. The sharper the focus of their message, the greater its chances of success.

3) Administrators need to consider the total physical and human setting. Meaning and intent are conveyed by more than words alone. Many other factors influence the overall impact of a communication, and administrators must be sensitive to the total setting in which they communicate: the circumstances under which an announcement or decision is made; the physical setting whether the communication is made in private or otherwise; the social climate that pervades work relationships within the school or department and sets the tone of its communications; custom and practice the degree to which the communication conforms to, or departs from, the expectations of the audience. Be constantly aware of the total setting in which you communicate. Like all living things, communication must be capable of adapting to its environment.

4) Administrators need to consult with others, when appropriate, in planning communications. Frequently, it is desirable or necessary to seek the participation of others in planning a communication or in developing the facts on which to base the communication. Such consultation often lends additional insight and objectivity to the message. Moreover, those who have helped plan the communication will give it their active support.

5) Administrators need to be mindful, while communicating, of the overtones as well as the basic content of the message. The administrator's tone of voice, expression, and apparent receptiveness to the responses of others all have tremendous impact on those the administrator wishes to reach. Frequently overlooked, these subtleties of communication often affect a listener's reaction to a message even more than its basic content. Similarly, the administrator's choice of languageparticularly her awareness of the fine shades of meaning and emotion in the words usedpredetermine in large part the reactions of the listeners. 
6) Administrators need to take the opportunity, when it arises, to convey something of help or value to the receiver. Consideration of the other person's interests and needs - trying to look at things from the other person's point of view frequently points up opportunities to convey something of immediate benefit or long-range value to the other person. Staff members are most responsive to administrators whose messages take staff interests into account.

7) Administrators need to follow up their communication. An administrator's best efforts at communication may be wasted, and she may never know whether she has succeeded in expressing her true meaning and intent if she does not follow up to see how well she has put her message across. An administrator can do this by asking questions, by encouraging the receiver to express his or her reactions, by follow-up contacts, and by subsequent review of performance. An administrator needs to make certain that every important communication has feedback so that complete understanding and appropriate action result.

8) Administrators need to communicate for tomorrow as well as today. Although communications may be aimed primarily at meeting the demands of an immediate situation, they must be planned with the past in mind if they are to maintain consistency in the receiver's view. Most important, however, communications must be consistent with long-range interests and goals. For example, it is not easy to communicate frankly on such matters as poor performance or the shortcomings of a loyal staff member, but postponing disagreeable communications makes these matters more difficult in the long run and is actually unfair to your staff and your school organization.

9) Administrators need to be sure that their actions support their communications. In the final analysis, the most persuasive kind of communication is not what administrators say, but what they do. When leaders' actions or attitudes contradict their words, others tend to discount what they have said. For every administrator, this means that good supervisory practices such as clear assignment of responsibility and authority, fair rewards for effort, and sound policy enforcement - serve to communicate more than all the gifts of oratory.

10) Administrators need to seek, not only to be understood, but to understand - be a good listener. When an administrator starts talking, he often ceases to listen, at least in that larger sense of being attuned to the other person's unspoken reactions and attitudes. Even more serious is the occasional inattentiveness a leader may be guilty of when others are attempting to communicate with him. Listening is one of the most important, most difficult, and most neglected skills in communication. It demands that the administrator concentrate not only on the explicit meanings another person is expressing, but also on the implicit meanings, unspoken words, and undertones that may be far more significant. Thus, an administrator must learn to listen with the inner ear if he is to know the inner person.

\section{RECEIVER'S RESPONSIBILITIES}

Communication depends on the ability not only to send but also to receive messages. So the ability to listen effectively greatly enhances the communication process. But many of us are not good listeners. Effective listening skills can be developed, however. Summarized following are ten rules for good listening (Kneen, 2011)):

1) Stop talking. You cannot listen if you are talking. For example, Polonius in Hamlet said: "Give every man thine ear, but few thy voice."

2) Put the talker at ease. Help a person feel free to talk. This is often called a permissive environment.

3) Show a talker that you want to listen. Look and act interested. Do not read your mail while someone talks. Listen to understand rather than to oppose.

4) Remove distractions. Don't doodle, tap, or shuffle papers. Will it be quieter if you shut the door?

5) Empathize with talkers. Try to help yourself see the other person's point of view.

6) Be patient. Allow plenty of time. Do not interrupt a talker. Don't start for the door or walk away.

7) Hold your temper. An angry person takes the wrong meaning from words.

8) Go easy on argument and criticism. These put people on the defensive, and they may clam up or become angry. Do not argue: Even if you win, you lose. 
9) Ask questions. This encourages a talker and shows that you are listening. It helps to develop points further.

10) Stop talking. This is first and last, because all other guides depend on it. You cannot do an effective listening job while you are talking. Nature gave people two ears but only one tongue, which is a gentle hint that they should listen more than they talk. Listening requires two ears, one for meaning and one for feeling. Leaders who do not listen have less information for making sound decisions.

\section{ACTIVE Listening}

Active listening is a term popularized by the work of Carl Rogers and Richard Farson (n.d.) and advocated by counselors and therapists (Brownell, 2009; Burstein, 2010). The concept recognizes that a sender's message contains both verbal and nonverbal content as well as a feeling component. The receiver should be aware of both components in order to comprehend the total meaning of the message. For instance, when a staff member says to her supervisor, "Next time you ask me to prepare a report, please give me some advance notice." The content conveys that the staff member needs time, but the feeling component may indicate resentment for being pressured to meet a deadline with such short notice. The supervisor, therefore, must recognize this feeling to understand the staff member's message. There are five guidelines that can help school administrators to become more active listeners (Rogers \& Farson, n.d.).

1) Listen for message content. The receiver must try to hear exactly what the sender is saying in the message.

2) Listen for feelings. The receiver must try to identify how the sender feels in terms of the message content. This can be done by asking: "What is he trying to say?"

3) Respond to feelings. The receiver must let the sender know that her feelings, as well as the message content are recognized.

4) Note all cues, verbal and nonverbal. The receiver must be sensitive to the nonverbal messages as well as the verbal ones. If the receiver identifies mixed messages, he may ask for clarification.

5) Rephrase the sender's message. The receiver may restate or paraphrase the verbal and nonverbal messages as feedback to the sender. The receiver can do this by allowing the sender to respond with further information. The last guideline is one of the most powerful of the active listening techniques and is used regularly by counselors and therapists. It helps the receiver avoid passing judgment or giving advice, and encourages the sender to provide more information about what is really the problem.

\section{Socialization as A Communication STRATEGY}

The socialization function of communication is stressed in the human relations perspective of institution which asserts that capturing the heart and minds of Public institution members is necessary to effectively coordinate Public institutional action in the pursuit of collective institutional goals. Communication directed at socializing Public institutional members focuses on articulating and reinforcing institutional values and aligning individual goals with institutional goals. It is directed at establishing an appropriate institutional culture and climate. This form of communication cannot be one-way or top-down. This must occur reciprocally between institutional leaders and institutional members.

Innovation: The Public institutional communication literature is increasingly addressing the importance of communication in promoting innovation as well as control and coordination. Communication to promote innovation is associated with strong communication within and beyond the institutional. This approach focuses on the functional goals of Public institutional communication, rather than on the near term outcomes of particular acts of communication, such as to make a decision to persuade, or to resolve a conflict. The more specific functions of specific functions of specific acts of communication or sets of communication exchange (decision-making, informing, persuading, negotiating, and problem-solving) are subsumed into each of the three higher-level functional objectives.

\section{NeW COMmunication TEChNOLOGIES AND COMMUNiCATION BARRIERS}

Presently there has been a sea change in communication technologies and a corresponding sea-change in communication theory and research. The institutional communication literature traditionally 
focused on how variation in Public institutional communication action were effected by variations in the size, structure and types of institutions and how different types of Public institutional culture gave rise to different types of institutional communication. The literature has now switched the causal ordering, emphasizing new forms of Public institutional structures, cultures, as well as wholly new institutional forms. New communication technologies and possibilities, combined with new challenges confronting institution and encouraging a whole new approach to Public institutional communication that challenges the very nature of institutions themselves. Practically new communication-enabled institutional forms possible and are now emerging (Tucker et al. 1996, Lucas 1996, Desantis and Fulk 1999). The most notable advances in communication technology are groupware or computer facilitated group communication technologies. Johasen (1984) distinguishes groupware in terms of temporal and spatial contexts. These communication technologies can help traditional group's network together more effectively. But more importantly, they help dispersed individuals work as a team.

Although, the coming of communication technologies has opened up new opportunities, scholars and practitioners recognized that neither the theory nor the practice of Public institutional communication has kept up with this rapidly changing situation. Public institutional communication "best practices," to the extend they exist, are typically years out-of-date (Sapienza 1995). Also the introduction of new communication technologies has caused problems as well as opportunities. Some communication technologies have led to communication overload. It is common fallacy to assure that because communication is generally seen as a good thing, the more communication the better communication overload is a real problem/barrier-what is needed is better, not more, communication (Richmond and McCroskey 1992, Conrad 1994)

\section{Theoretical Perspectives}

It is commonly held that public relations lack a comprehensive theoretical foundation. It is argued in this study that in general, although not exclusively, much of the theoretical work in public relations has not granted the process of communication its full importance. It is further argued that the discipline of communication science, therefore, is the logical theoretical foundation for the field and that it offers a much needed 'philosophical' point of departure fdr the field of public relations. It is suggested that the public relations field may be reasonably described as in a transitional phase of 'struggle' as it tries to reconcile and situate its activities within the form of an ethical science and in so doing adopt a broader, more humane social vision, in which accountability to its stakeholders is accorded its full importance. If public relations is viewed as a function concerned with the management of relationships between an organization and its publics, the form that such relationships may take and the specific role which public relations plays in their management must still be clarified. Traditionally, public relations has been portrayed as a simple communication' function. However, in many cases the definition of communication is restricted largely to the transmission and reception of information, usually with the aim of influencing or modifying attitudes and opinions the view that 'public relations programmes may need ultimately to bring about a behavioural change in order to achieve their objectives" (Stirling 1993). Various communication theories in public relations or communication have been proposed. This paper made use of some theoretical perspectives to situate the present study within existing literature.

\section{Mixed Motive/Game Theory}

Another term used for divided loyalties is mixed motives, a concept from game theory that Murphy (1991:120) introduced to public relations theory. She argues that most of those who strongly advocate symmetric communication admit that it is extremely rare in actual practice. However, Murphy goes on to propose a 'middle ground' based on game theory, rather than the zero-sum game which characterizes one-way communication. Murphy proposes a definition of public relations as a mixed motive game to help reconcile the divergent symmetric versus asymmetric models. She sees public relations as "a sliding scale of co-operation and competition in which organizational needs of necessity be balanced against constituents' needs, but never lose their primacy". In simple terms, Murphy's mixed motive game positions public relations on a sliding scale of action somewhere between pure conflict and pure symmetry. Over thirty years ago, the functionalist sociologist AIvin Gouldner (1960) wrote that a "norm of reciprocity" is a universal component of moral codes. He refers to Aristotle's observation that people are "more ready to receive than to give benefits. People 
tend towards egoism, he said, "a salient (but not exclusive) concern with the satisfaction of one's own needs.

Balancing the Dilemma of Unequal Power In short, excellent organizations realize that they can get more of what they want by giving their publics some of what they want. Reciprocity means that publics, too, will be willing to give up some of what they want to the organization. The logic of reciprocity breaks down, however, when one actor (such as an organization) has more power than another (such as a public). "Given significant power differences," according to Gouldner (1960), "egoistic motivations may seek to get benefits without returning them". Rakow (1989), for example, criticized the symmetrical approach to public relations as impractical because she believed that organizations in the US social system, at least, have more power than publics and therefore have no motivation for reciprocity. Mallinson (1990) similarly argued that the two-way symmetrical model would work better in the more egalitarian cultures of Europe than it would in the United States. And Pavlik (1989) showed, in game theory terms, that organizations are unlikely to practice public relations symmetrically until publics gain equal power. The dilemma of unequal power has been partially resolved because publics have gained power by organizing themselves into activist groups. But in many relationships with publics, organizations still hold the upper hand. In that case, Gonldner (1960) proposes that a "generalized norm of reciprocity" would solve the dilemma of unequal power. Most moral codes, he says, contain a norm that reciprocity is good or necessary - even if people or organisations can get what they want by exerting their power. Organizations that do not adhere to this general norm lose the trust and credibility of the larger society of which they are a part. Thus, excellent organizations would seem likely to incorporate the norm into their business or organizational ethics and, in turn, into their public relations ethics. The norm of reciprocity is the essence of what generally is called social responsibility.

\section{The Social Role of Public Relations}

This discussion of asymmetrical and symmetrical world views about public relations touches on concepts such as the community, the social system and social responsibility. Most practitioners and scholars have presuppositions about the social role of public relations, even though they may not articulate them or be aware of them. It can be argued, therefore, that some of these extant presuppositions enhance the excellence of public relations and others detract from it. In addition some are symmetrical and some are asymmetrical.

\subsection{Pragmatic Social Role}

Grunig and White (1992:36) argue that the pragmatic social view is common in public relations because of its concern for doing what the clients wants. However, this view is not conducive to excellence, and seldom makes the organization more effective.

\subsection{Conservative Social Role}

According to the conservative presupposition, public relations defend and maintain the status quo. See, for example, Tedlow (1979) who describes public relations as a "defensive political device." Pimlott (1951) suggests that public relations justifies and defends the privileges of the economically powerful and that public relations practitioners, like politicians and teachers, are essentially articulate apologists for a social system based on what are, in some cases, insupportable inequalities. Sussman (1949) describes public relations as based on a defensive ideology. Modem reflections of this view are found in the writings of Philip Lesley (1984) in books such as Overcoming Opposition, which explains how public relations can overcome threats to the status quo. In practice, a conservative view of the social role leads practitioners to adopt a defensive or protective outlook on their client's interests that is, an asymmetrical outlook. Practitioners with this social view also see society in conservative terms. They believe in defending the status quo and an idealized capitalist system from attack.

\subsection{Radical Social Role}

The radical world view presupposes that public relations contribute to change, within organizations and in society. It does so by providing an outside perspective to management about the organization and its internal functioning. In the wider society, public relations contributes to social change by providing information for use in public debate, by establishing links between groups in society, and by bringing together resources that can be brought to bear on the solution of social problems. This 
world view also sees society as a system in which knowledge and information provide power and influence, which in turn can be used to bring about change. Goldhaber et al. (1979) argue, for example, that power and influence within organizations now have passed to people such as public relations practitioners, who can provide information about the environment to decision makers. Hofstede (1980) argues that practitioners should act as agents of change within organizations, to help them to adjust to changing public expectations.

\subsection{Idealistic Social Role}

Idealistic presuppositions about public relations appear in codes of conduct, definitions of the practice and academic writing about the practice. This world view presupposes that public relations serves the public interest, develops mutual understanding between organizations and their publics, contributes to informed debate about issues in society, and facilitates a dialogue between organizations and their publics. This world view sees society as emerging from compromise from the peaceful resolution of conflict between groups iu society. It assumes a pluralist and progressive society, iu which a diversity of views and their reconciliation lead to social progress. Excellent public relations practice in this context therefore, generally will be symmetrical and idealistic.

\section{Communication Models in Public Relations}

More recently, a school of research in communication has flourished which has developed out of the ideas of balance, congruence and seeking of supportive information. McLeod and Chaffee (1973) have labelled this new tradition the 'co orientation approach. '

\subsection{Co-orientation Model}

The key features of this approach are a focus on interpersonal communication and on communication which is two-way and interactive; an emphasis on the simultaneous inclusion in any study of the three main elements of information sources, communicators and receivers; and an interest in the dynamics of communication situations. The model depicts a common finding of research on public opinion and communication: information about an event or issue is sought from or acquired by members of the public by reference to personal experience, or elite sources, or the mass media, and often from a combination of these. The outcome of what is a dynamic situation will thus depend on the relationships between public and a given elite, on the attitude of the public to the media and in the relationships between elite sources and media channels. (McQuail and Windahl 1981). In a study of mass media use and opinion about community issues, Tichenor et al. (1973) confirmed an initial expectation that the definition of an issue as controversial leads to more learning from the media about that issue. This work was carried out with reference to the existence and development of knowledge groups; this approach is particularly relevant to research in convergence and divergence in opinion an!! information levels between given social groups or categories.

\subsection{Open and Closed Systems}

According to Cutlip et al. (1985:192-196), output of a steady stream of press releases and other traditional reactive public relatious respouses is suggestive of 'closed systems' thinking. This all too common approach is based on the notion that the purpose of public relations is limited to effecting changes in the environment. On the other hand, the open systems approach puts public relations squarely in the middle of bringing about changes both in the environment and in the organization itself as a result of environmental inputs. Bell and Bell (1976) make a similar distinction, referring to functionary and functional approaches to public relations. The functionary role is similar to the closed system approach:

Public relations functionaries attempt to preserve and promote a favorable image of the organization in the co=unity on the hypothesis that if the organization is 'liked,' the public will continue to absorb the organization's outputs. Such functionaries are only concerned with supplying information about the organization to the environment and not with supplying information about the environment to the organization. Because functionaries do not supply feedback information, they do not function in decision-making or even in advisory roles in relation to environmental concerns. Therefore, they have little to say about 'what' is said; they are mainly concerned with 'how' things are said. (Cutlip et al., 1985) 
In this approach to public relations, the emphasis is on maintaining the status quo in the organization while effecting change on the parts of the organization's publics. Relations between the organization and its publics are changed only to the extent that the publics are brought into line with the organization.

In contrast, a functional view of public relations calls for an 'open systems' approach, using both input and output to change both the organization and the environment. Relations between the organization and its publics are maintained or changed on the basis of reciprocal output-feedback-adjustment. In this approach, public relations have the potential to act in an advisory capacity and to have impact on decision-making. This potential in turn leads to some control over its own domain in times of crisis and, as a sensing device, public relations can be effective in preventing many potential crisis situations. Management properly remains the 'large wheel' but the small wheel that is public relations may occasionally be capable of influencing the larger one. If observations of external and internal environments indicate that a policy or practice is detrimental to the best interests of the organization (and, increasingly, society) management can be encouraged to adjust. (Cutlip et al., 1985:193). The functionary mode limits the public relations practitioner to a technician's role. The environment is monitored (if at all) for the sole purpose of making communication output more effective, not to bring about changes within the organization. Grunig and Hunt (1984:22) estimate that 85 per cent of all organizations practice public relations in ways consistent with the functionary role. In organizations where public relations operate in the functional mode, practitioners are managers - combining the roles of expert prescriber, communication process facilitator and problem-solving process facilitator.

\subsection{An Open Systems Model of Public Relations}

It may be argued that an open systems approach to public relations suggests radical departures from the widely used functionary approach. This approach which Grunig and Hunt (1985) call the 'two-way symmetric' model, stresses that communication is reciprocal and that the information exchange modifies both sides of organisation-public relationships. As discussed earlier Chaffee and Patrick (1975) adopt a similar concept of corporate public relations, defining it as helping both the corporation and its public get more correct pictures of one another; it also would employ communication as a tool to help both corporations and citizens solve problems. In such an approach, communication strategies are designed for the sharing (not just giving) of information and for the solving (not just explaining away) of problems. Although Chaffee and Patrick refer only to corporations, this approach also emphasizes the primary role of communication in social systems in general. As Buckley (1967) puts it, "the interrelations characterising higher levels (of systems) come to depend more and more on the transmission of information - a principle fundamental to modem complex system analysis". Applying the open systems approach to public relations calls for the purposeful scanning of the environment to detect and anticipate changes that affect the organization's relationships with its publics. Following an open systems approach, public relations must be selectively sensitive to those publics that are mutually affected and/or, involved by the organization's policies, procedures and actions. This not only calls for specifically defmed publics, but also for the research skills to monitor publics as well as the organization itself. Open systems public relations also has the capacity for initiating corrective actions within the organization and for directing efforts to affect knowledge, predispositions and behaviours of the public's. (Cutlip et al., 1985) The dynamics sought in this model are the maintenance or achievement of goals that are in the organization's and the publics' mutual interests. Those found to be in conflict with mutual interests are changed or eliminated. Proactive corrective action may be the major and most useful aspect of the open systems model of public relations. Preventive measures require less effort and trauma than crisis-orientated reactive public relations. Thus, organizations employing open systems public relations maintain their relationships by adjusting and adapting themselves and their publics to ever-changing social, political and economic environments.

\subsection{Recommendations To Institutions/ Ndu Council}

Based on literature and theoretical positions, the following recommendations have been made to greatly improve institutional effectiveness as concerns communication. Considering the fact that communication is one of the toughest issues in institutions especially public institutions. For communication to be effective, administrators should be aware of communication process and barrier that interfere with the successful communication of messages. An important method of effective communication involves four steps: 
- Knowing the barriers to communication

- Predicting when those barriers may occur within any given communication situation,

- Identifying those barriers when they do occur, and

- Developing strategies to overcome them.

Effective communication is significant for administrators in the institutions so as to perform the basic functions of management, i.e., planning, organizing, leading and controlling. The following are solutions to the identified challenges of communication barriers:

1) Language barriers: Several potential solutions might be addressed here including posting signs in employees' primary language. Putting signage with visuals, not just words. In institutions some simple words in the employees' primary language to help show interest in the employees. Have a language of communication which will be understood by the decoder. The content of the message has to resonate and connect, on some level, with the already held beliefs of the receiver.

2) Generational (age) barriers: Currently there are four generations in the workforce and each potentially has a different preferred method of communication. While the younger generation might prefer to receive text messages as their preferred way of communication, older employees may not find this method of communication acceptable. Consider your employee's preferences and be willing to communicate a message in a few different ways.

3) Cultural and ethnic barriers: Institutions need to identify cultural beliefs and work to understand the ethnic barriers.

4) Non verbal challenges: An administrator's appearance is a nonverbal cue to employees. Administrator's appearance is important as he is a role-model to the employees. His actions and behaviors should be consistent with what he is expecting of them. For example, because he is expecting the employees to follow proper hand washing procedure, he should also use proper hand washing procedures.

5) Emotional barriers: Emotional barriers can interfere with effective communication. It will be important for administrators/employees to get their emotions "in check" prior to starting work. Having self-awareness and potentially seeking outside assistance (i.e. Employee Assistance Programs) may be possible solutions here.

Communication helps administrators to perform their jobs and responsibilities. Communication serves as a foundation for planning. All the essential information must be communicated to the administrators who in-turn must communicate the plans so as to implement them. Organizing also requires effective communication with others about their job task. Similarly leaders as administrators must communicate effectively with their subordinates so as to achieve institutional goals. Controlling is not possible without written and oral communication. Administrators should devote a greater part of their time in communication. They should devote at least six (6) hours per day in communicating especially face to face or telephonic communication. They should spend time with their superiors, subordinates, colleagues, staff. Administrators should also use written communication in forms of letters, report or memos wherever oral communication is not feasible. Thus, we can say that "effective communication is a building block of successful public institutions." In other words, communication acts as institutional blood.

\section{CONCLUSION REMARKS}

In advocating an open system, the public relations profession, through its practitioners, has the opportunity of placing itself in a broader social and ethical context. For this to happen, however, it will be necessary for the profession to evaluate its current practices and at the same time to foster greater independence of thought and action. Communication is the process of transmitting information and common understanding from one person to another. The elements of the communication process are the sender, encoding the message, transmitting the message through a medium, receiving the message, decoding the message, feedback, and noise. A number of barriers retard effective communication. These can be divided into four categories: process barriers, physical barriers, semantic barriers, and psychosocial barriers. To improve the effectiveness of communications, institutions must develop an awareness of the importance of sender's and receiver's responsibilities and adhere to active listening skills. 


\section{REFERENCES}

Abrell, R. (2004). Preventing communication breakdowns. Reston, VA: National Association of Secondary School Principals.

Antos, G. (2011). Handbook of interpersonal communication. The Hague, The Netherlands: Mouton De

Bell, S.H. and Bell, E.C. 1976. Public relations: functional or functionary. Public Relations Review Vol 2 (Summer 1976).

Boston, MA: Pearson. Weiss, B. (2011). How to understand language: A philosophical inquiry. Montreal, QUE: McGill University Press.

Brownell, J. (2009). Listening: Attitudes, principles, and skills. Boston, MA: Pearson.

Brun, J. P. (2010). Missing pieces: 7 ways to improve employee well-being and organizational effectiveness. New York, NY: Palgrave Macmillan.

Burstein, J. (2010). Have you heard?: Active listening. New York, NY: Crabtree Publishing.

Canary, H. (2011). Communication and organizational knowledge: Contemporary issues for theory and practice. Florence, KY: Taylor \& Francis.

Cheney, G. (2011). Organizational communication in an age of globalization: Issues, reflections, practices. Long Grove, IL: Waveland Press.

Cutlip, S.M., Centre, A.M. and Broom, G.M. 1985. Effective public relations. Englewood Cliffs, New Jersey: Prentice Hall.

Eisenberg, E. M. (2010). Organizational communication: Balancing creativity and constraint. New York, NY: Saint Martin's.

Gouldner, A.W. 1960. The norm of reciprocity: a preliminary statement. American sociological review 25:161-178.

Green, R. L. (2010). The four dimensions of principal leadership: A framework for leading 21st century schools. Boston, MA: Pearson.

Gruyter. Auer, P. (2011). Theories and methods. The Hague, The Netherlands: Mouton De Gruyter.

Hofstede, E. 1980. Angola coffee - or the confrontation of an organisation with changing values in its environment. Organisation Studies (21-40).

Keyton, J. (2010). Case studies for organizational communication: Understanding communication processes. New York, NY: Oxford University Press.

Keyton, J. (2011). Communication and organizational culture: A key to understanding work experience. Thousand Oaks, CA: Sage.

Kneen, J. (2011). Essential skills: Essential speaking and listening skills. New York, NY: Oxford University Press. FRED C. LUNENBUR

Larson, R. K. (2011). The evolution of human language: Biolinguistic perspectives. New York, NY: Cambridge University Press.

Lunenburg, F.C,\& Irby, B. J. (2006). The principalship: Vision to action. Belmont, CA: Wadsworth/Cengage.

Lutgen-Sandvik, P. (2010). Destructive organizational communication: Processes, consequences, and constructive ways of organizing. New York, NY: Routledge.

Mallinson, B. 1990. Bridging the gap between theory and practice in post-1992 Europe: the changing face of public relations. Paper presented at a meeting of the International Communication Association: Dublin.

Matthews, L. J., \& G. M. Crow (2010). The principalship: New roles in a professional learning community. Boston, MA: Pearson.

McLeod, I.M. and Chaffee, S.H. 1973. Interpersonal approaches to communication research. American Behavioral Scientist Vo!. 16 (March/April).

McQuail, D. and Windah, S. 1981. Communication models for the study of mass communications. London: Longman

Murphy, P. 1991. Limits of symmetry. Public Relations Research Annual. Vol. 3. Lawrence Erlbaun Associates.

Pauley, J. A. (2010). Communication: The key to effective leadership. Milwaukee, WI: ASQ Quality Press. Rogers, C. R., \& Farson, R. F. (n.d.). Active listening. Chicago, IL; Industrial Relations Center, University of Chicago. 
Dynamics of Communication Barriers on Public Institutions; The Case of NDU Council, North West Region Cameroon

Pavlik, J.V. 1989. The concept of symmetry in the education of public relations practitioners. Paper presented at the meeting of the International Communication Association: San Francisco.

Routledge. Ubben, G. C., Hughes, L. W., \& Norris, C. J. (2010). The principal: Creative leadership for excellence in schools (7th ed.).

Sergiovanni, T. J. (2009). The principalship: A reflective practice perspective. Boson, MA: Pearson.

Shaw, G. B. (2011). The wit and wisdom of George Bernard Shaw. Mineola, NY; Dover Publications.

Shettleworth, S. J. (2010). Cognition, evolution, and behavior. New York, NY: Oxford University Press.

Stirling University. 1990. M.Sc. in Public Relations Course. The nature and defInitions of public relations, Unit 2, Module 1.

Summers, D. C. (2010). Quality management: Creating and sustaining organizational effectiveness. Upper Saddle River, NJ: Prentice Hall.

Sussman, L.A. 1949. The personnel and ideology of public relations. Public Opinion Quarterly, 12:697-708.

Tareilo, J. (2011). Other side of the desk: A 20/20 look at the principalship. Lanham, MD: Rowman \& Littlefield. Tourish, D. (2010). Auditing organizational communication: A handbook of research, theory, and practice. New York, NY:

Tedlow, R.S. 1979. Keeping the corporate image: public relations and business 1900-1950. Greenwich, CT: JA!.

Yate, M. (2009). Hiring the best: A manager's guide to effective interviewing and recruiting. Cincinnati, OH: F \& W Media.

\section{AUTHORS' BIOGRAPHY}

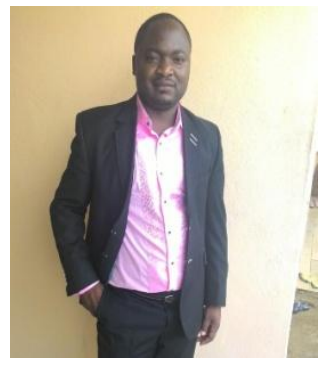

Massa Ernest Massa, is a Lecturer at Higher Technical Teachers Training College (H.T.T.T.C) Kumba an integral school of the University of Buea. He has a Master's Degree in Educational Administration and Foundations alongside a Bachelor's Degree in Political Science and Public Administration/ Public Law from the University of Buea. Massa Ernest Massa also has a Teacher Training Diploma (DIPET II) in Information Management And Communication, Administrative Techniques from ENSET Bambili, University of Bamenda $\mathrm{He}$ is currently a teacher of Information Management and Communication, Administrative Techniques at GTHS Tiko. He is a member of the Cameroon National Youth Council. Massa Ernest Massa is a renowned Researcher working with the Foundation of Scientific Research, Community Based Rehabilitation and Advocay on Inclusive Education (Forcaie- Cameroon)

Dr Lukong Kenneth Mengjo, is a Senior Lecturer of Political Science and Conflict Resolution. He is a renowned educationist within the higher Educational circles in Cameroon. He studied in Nigeria and Russia for Higher Educational degrees. Dr Lukong Kenneth has worked in the University of Dschang where he held several positions. Based on his contributions in terms of Administrative Productivity, Teaching And Research, Dr Lukong Kenneth was appointed as the Pioneer Director of HTTTC UBa. $\mathrm{He}$ is currently the Dean of Studies, ENSET Kumba, University of Buea. He is a dynamic, prolific Cameroonian vested with a sound knowledge in Political sciences and conflict resolution. He has supervised more than fifty thesis and has continuously been a reference point among his peers to most of his students. Among Dr Lukong Kenneth numerous publications is "Dilemmas Over Individual And State Responsibility For Violations Of International Humanitarian Law" which attempts an explanation to some of the complex legal issues surrounding the whole concept of responsibility for violations of international humanitarian law with reflections on the violations of international humanitarian law adopted by the international law commission as well as opinions of experts on the subject, treaties, conventions, international jurisprudence, and internationally recognized principles and customs that govern conduct in armed conflicts so as to limit human suffering particularly of non combatants. 